Pak. j. sci. ind. res. Ser. B: biol. sci. 201558 (2) 83-91

\title{
Application of Extrusion Technology to Prepare Bread Crumb, A Comparison with Oven Method
}

\author{
Imran Pasha, Muhammad Farhan Jahangir Chughtai*, Arsalan Sarwar, Muhammad Asim \\ Shabbir and Shabbir Ahmed \\ National Institute of Food Science and Technology, University of Agriculture, Faisalabad, Pakistan
}

(received December 30, 2014; revised June 5, 2015; accepted June 16, 2015)

\begin{abstract}
The current research project was designed to conclude the upshot of extrusion cooking temperature on the properties and acceptability of bread crumb. Bread crumbs were obtained by drying the bread, maintaining moisture up to $3-8 \%$ and then broken down using hammer mill or crusher which breaks the bread into bread crumbs. Significantly highest moisture contents $7.26 \%$ was observed in oven baked bread crumb as compared to $6.25 \%$ in bread crumb prepared by extrusion cooking method. The highest bulk density $(28.13 \mathrm{~g} / 100 \mathrm{~L})$ was observed in extruded bread crumb whereas, the oven baked bread crumbs showed lower bulk density $(7.03 \mathrm{~g} / 100 \mathrm{~L})$. The fat uptake of extruded and oven baked bread crumbs were found $0.516 \mathrm{mg} / \mathrm{g}$ and $0.493 \mathrm{mg} / \mathrm{g}$, respectively. The extruded bread crumb showed higher water binding capacity as $34.76 \mathrm{~g} \mathrm{H}_{2} \mathrm{O} / \mathrm{kg}$ as compared to oven baked bread crumb which showed $27.92 \mathrm{~g} \mathrm{H} \mathrm{H}_{2} \mathrm{O} / \mathrm{kg}$. Sensory evaluation of extruded and oven baked bread crumbs depicted that bread crumbs prepared from extrusion cooking methods got significantly higher scores for taste, flavour and over all acceptability as compared to those prepared by oven baked method. As far as crispiness is concerned oven baked bread crumbs got comparatively higher scores. Moreover, it was concluded that the treatment $\mathrm{T}_{2}$ of extruded bread crumbs got more sensory scores than oven baked bread crumbs.
\end{abstract}

Keywords: bread crumb, extrusion technology, oven method, sensory evaluation

\section{Introduction}

Wheat flour bread is the staple food in many countries (Altamirano-Fortoul et al., 2012). Bread plays key role in our balanced food due to the presence of starch and other carbohydrates (Rosell, 2009). Bread is directly consumed and is also used for the production of bread crumb which is bread by-product. Bread crumbs are made by drying bread generally at ambient environments and its purpose is prevention from further gelatinization and breakdown of starch. The dried material is then mildly milled to prevent uninvited destruction of starch granules which is then sieved according to desired particle sizes. Bread crumbs have several applications in food products and used as a main ingredient in processing food products, such as the breading fried food and also used as a coating on confectioneries. Bread crumbs increase the stability of food and therefore, permit industries to supply and produce bread crumbs for fish stick or fish finger and also for other fried food (Shittu et al., 2007).

Coatings can even be applied to the food items to create a good seal off against moisture loss. Although by reheating, coatings will reabsorb moisture associated

*Author for correspondence;

E-mail: m.farhan.chughtai@hotmail.com with nutrition and up to desirable content, crispy external outside together with conserving, with saving all natural flavour and with nutritive valuation within the food nutrition (Yu and Augustine, 2002). Bread crumb is a typical component within the food industry as possibly utilized for coating or filling of stuffed pasta. It may be used in dried layer to produce a good exterior coating more than various food formulations. The quantity of bread crumb may vary and signify as much as $40 \%$ from the filling (personal likeness), based on the specific formula of the final item resulting in high quality as well as have high features. Primarily, the actual assimilation is associated with absorption of water as well as fat elements during cooking food by the crumbs and also contribute final volume of the filling. Therefore, it is cheaper and economical as compared to costly elements, for example cheese, and other raw materials, etc. Definitely, an essential technical role of bread crumbs may be the accomplishment of the practical filling with a commercial forming as well as filling device (Pajak et al., 2012).

Appealing textural qualities associated with bread tends to be mainly based on their specific cellular morphology (porosity, size of air tissue, interconnectivity, thickness of beam, thickness of brown crust area, and so on.), 
elements as well as water content. Qualities associated with brown crust area and crumb will vary, brown crust area is dryer, tougher, darker as well as denser and may end up from the crumb depending on these types of requirements (Vanin et al., 2009). Clusters of amylose as well as amylopectin made an appearance within the crumb after baking. These clusters had been ghosts of starch granules by which amylose offers focused in the centre as well as amylopectin is situated in the border from the ghosts of starch granules (Hug-Iten et al., 1999).

Extrusion cooking food is really a continual cooking, mixing, as well as developing procedure. The extrusion is inexpensive, flexible as well as efficient technologies (Guy, 2001). The raw material go through numerous reactions as well as structural changes throughout extrusion cooking food, for example starch gelatinization, amylose as well as proteins denaturation, retain nutritional vitamins and colours, etc. (Ilo and Berghofer, 1999). Using extrusion cooking food may be manufacturing associated with meals for example breakfast every day cereals, modified starches, fiat bread as well as cheese analogues and infant meals.

Customers usually love the foods having a fried-like flavour as well as consistency (Yu and Augustine, 2002). As a result, the food business offers replied through building items, that on traditional oven reheating lead to food having a fried-like consistency as well as flavour. Breads crumb-like items in many cases are utilised in the food business to improve fried-like consistency associated with food. In the view of these facts, the present project was carried out to determine the outcome of extrusion cooking temperature on the properties and acceptability of bread crumb prepared by oven baking and extrusion cooking method.

\section{Materials and Methods}

Materials. Wheat flour and defatted soy flour, baking powder, sugar, salt and emulsifier, yeast used in this project were purchased from the local market.

Preparation of bread crumb by oven. The breads were prepared according to the AACC (2000) straight dough method No. 10-10B. The ingredients were mixed for 5-10 min in a Hobart A-200 Mixer to form dough and allowed to ferment at $30{ }^{\circ} \mathrm{C}$ and $75 \%$ R.H. for 180 min. First and second punches were made after 120 and $150 \mathrm{~min}$, respectively. The dough was molded and panned into $100 \mathrm{~g}$ test pans, and final proofing was done for 45 min at $95^{\circ} \mathrm{F}\left(35^{\circ} \mathrm{C}\right)$ and $85 \%$ R.H. The bread was baked at $232{ }^{\circ} \mathrm{C}$ for $13 \mathrm{~min}$. The bread was dried and the moisture content at the drying step was about $3-8 \%$. The bread was then placed into a hammer mill or crusher which breaks the bread into crumbs. Treatments from $\mathrm{T}_{0}$ to $\mathrm{T}_{4}$ contain different moisture contents. Moisture contents from different treatments are presented in Table 1 .

Table 1. Treatment plan for oven baked bread crumb (bread crumb will be prepared in oven at $200 \pm 20^{\circ} \mathrm{C}$ temperature by using following formulation)

\begin{tabular}{lllllll}
\hline \hline $\begin{array}{l}\text { Treat- } \\
\text { ment }\end{array}$ & Flour & Sugar & Salt & Yeast & Emulsifier & $\begin{array}{l}\text { Moisture } \\
\text { of crumb } \\
(\%)\end{array}$ \\
\hline $\mathrm{T}_{0}$ & 100 & 3 & 1 & 3 & 5 & 3.55 \\
$\mathrm{~T}_{1}$ & 100 & 3 & 1 & 3 & 5 & 4.76 \\
$\mathrm{~T}_{2}$ & 100 & 3 & 1 & 3 & 5 & 6.17 \\
$\mathrm{~T}_{3}$ & 100 & 3 & 1 & 3 & 5 & 6.52 \\
$\mathrm{~T}_{4}$ & 100 & 3 & 1 & 3 & 5 & 7.26 \\
\hline \hline
\end{tabular}

Preparation of bread crumb by extrusion. The extruder used in this project was an experimental extruder model SYSLG30.VI co-rotating twin screw equipped with two barrel sections. Extrusion was done at optimised conditions of temperature and pressure and die configuration. The screws were $5.55 \mathrm{~cm}$ in diameter and had an overall active length of $50 \mathrm{~cm}$. The extruder was operated at 150 and $155 \mathrm{rpm}$. A $14.7 \mathrm{KW}$ DC motor was used to drive the extruder. Moisture content of the feed was controlled at $27-30 \%$ by injecting water. An adjustable cutter with four blades facing the die was operated at $300 \mathrm{rpm}$ to cut the extrudate as it emerges from the extruder. Extruder temperatures measured by a PC computer were $120^{\circ} \mathrm{C}$ for the extruded samples, respectively. Glycerol solution $(20 \%)$ was injected into the barrel during extrusion in some cases. The extrudates (pellet) were dried in an oven at $100{ }^{\circ} \mathrm{C}$ for $35 \mathrm{~min}$ (Yu and Augustine, 2002). Formulations of different treatments are presented in Table 2 .

Analysis of bread crumbs. The moisture content was determined by oven drying the bread crumb samples at $100{ }^{\circ} \mathrm{C}$ to constant weight and loss in weight will be expressed as moisture as described in Method No. 92608. AACC (2000). The bulk density was calculated by dividing the weight of extrudates by its volume presented by method of Hwang and Hayakawa (1980). 
Table 2. Treatment plan for the preparation of extruded bread crumb (bread crumbs were prepared by using following formulation)

\begin{tabular}{llllllll}
\hline \hline Treatment & Temperature $\left({ }^{\circ} \mathrm{C}\right)$ & Flour $(\%)$ & Sugar $(\%)$ & Salt $(\%)$ & Baking powder & Emulsifier $(\%)$ & Soy flour (\%) \\
\hline $\mathrm{T}_{0}$ & 120 & 88.7 & - & 2 & 4 & 0.3 & 5 \\
$\mathrm{~T}_{1}$ & 120 & 90.7 & - & 2 & 2 & 0.3 & 5 \\
$\mathrm{~T}_{2}$ & 110 & 85.3 & 3.4 & 2 & 4 & 0.3 & 5 \\
$\mathrm{~T}_{3}$ & 120 & 85.3 & 3.4 & 2 & 4 & 0.3 & 5 \\
$\mathrm{~T}_{4}$ & 130 & 85.3 & 3.4 & 2 & 4 & 0.3 & 5 \\
\hline \hline
\end{tabular}

Colonna et al. (1983) has shown that the value obtained by dividing the cross sectional area of the rod shaped extrudate by the cross sectional area of the diameter of the die is termed as expansion of extrudate. Fat uptake by the bread crumb was measured as described by $\mathrm{Yu}$ and Augustine (2002). While for the determination of water binding capacity of bread crumbs, the method devised by Lucisano et al. (2010) was adopted.

Sensory evaluation. The extruded and oven baked bread crumb samples were coated on cutlasses and served for sensory evaluations to a panel of judges from the staff and postgraduate students of National Institute of Food Science And Technology (NIFSAT). A 09 point hedonic scale (from $1=$ extremely dislike to $9=$ extremely like) was used to determine the preference in flavour, taste, crispiness and overall acceptability according to the procedure described by Lawless and Heymann (1998).

Statistical analysis. The data obtained was analysed statistically as described by Steel et al. (1997). The data was analysed by Complete Randomized Design (CRD) and the mean values of replications of different treatments were calculated by LSD at 0.05 .

\section{Results and Discussion}

This research was aimed to establish the standardised recipe of bread crumb by oven and extrusion methods.
The extrusion parameter studied includes extrusion temperature. This is the major factor known that affect extruder performance, product density, expansion ratio, colour, textural and sensory characteristics of extrudates.

Analysis of bread crumb. Moisture content. An important parameter for consumer acceptability is frying and affected by moisture content of the bread crumbs. According to results, the moisture content of extruded and oven baked bread crumb have highly significant effect. The moisture content of extruded and oven baked bread crumb are given in Table 3 and graphically expressed in Fig. 1. The moisture content of extruded bread crumb varied from 4.12 to $6.25 \%$, while that of oven baked bread crumb, it varied from 3.55-7.26\% among different

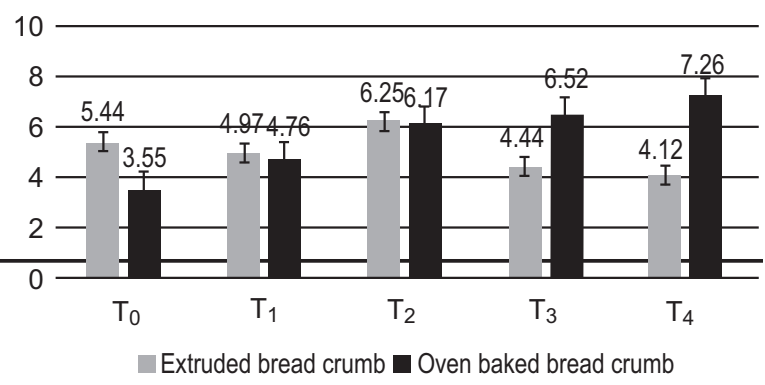

Fig. 1. Moisture content (\%) in extruded and oven baked bread crumb.

Table 3. Means table regarding moisture, bulk density, fat uptake and water binding capacity in extruded and oven baked bread crumb

\begin{tabular}{|c|c|c|c|c|c|c|c|c|}
\hline \multirow[b]{2}{*}{ Treatment } & \multicolumn{2}{|c|}{ Moisture content } & \multicolumn{2}{|c|}{ Bulk density } & \multicolumn{2}{|c|}{ Fat uptake } & \multicolumn{2}{|c|}{ Water binding capacity } \\
\hline & $\begin{array}{l}\text { Extruded } \\
\text { bread crumb }\end{array}$ & $\begin{array}{l}\text { Oven baked } \\
\text { bread crumb }\end{array}$ & $\begin{array}{l}\text { Extruded } \\
\text { bread crumb }\end{array}$ & $\begin{array}{l}\text { Oven baked } \\
\text { bread crumb }\end{array}$ & $\begin{array}{l}\text { Extruded } \\
\text { bread crumb }\end{array}$ & $\begin{array}{l}\text { Oven baked } \\
\text { bread crumb }\end{array}$ & $\begin{array}{l}\text { Extruded } \\
\text { bread crumb }\end{array}$ & $\begin{array}{l}\text { Oven baked } \\
\text { bread crumb }\end{array}$ \\
\hline $\mathrm{T}_{0}$ & $5.44 \pm 0.34^{\mathrm{b}}$ & $3.55 \pm 0.15^{\mathrm{d}}$ & $6.36 \pm 0.44^{\mathrm{c}}$ & $27.46 \pm 0.98^{\mathrm{ab}}$ & $0.423 \pm 0.003^{\mathrm{c}}$ & $0.403 \pm 0.0019^{\mathrm{ab}}$ & $32.23 \pm 1.1^{\mathrm{c}}$ & $27.76 \pm 1.6^{\mathrm{a}}$ \\
\hline $\mathrm{T}_{1}$ & $4.97 \pm 0.25^{\mathrm{bc}}$ & $4.76 \pm 0.25^{\mathrm{c}}$ & $6.46 \pm 0.49^{\mathrm{bc}}$ & $26.90 \pm 0.74^{\mathrm{abc}}$ & $0.403 \pm 0.0012^{\mathrm{c}}$ & $0.423 \pm 0.0015^{\mathrm{b}}$ & $30.50 \pm 1.9^{\mathrm{bc}}$ & $27.63 \pm 1.01^{\mathrm{a}}$ \\
\hline $\mathrm{T}_{2}$ & $6.25 \pm 0.43^{\mathrm{a}}$ & $6.17 \pm 0.49^{b}$ & $6.90 \pm 0.24^{\mathrm{ab}}$ & $28.13 \pm 0.81^{\mathrm{a}}$ & $0.516 \pm 0.0024^{\mathrm{a}}$ & $0.476 \pm 0.0024^{\mathrm{a}}$ & $28.96 \pm 0.89^{b}$ & $27.15 \pm 1.06^{\mathrm{b}}$ \\
\hline $\mathrm{T}_{3}$ & $4.44 \pm 0.22^{\mathrm{cd}}$ & $6.52 \pm 0.51^{b}$ & $6.66 \pm 0.31^{\mathrm{abc}}$ & $26.16 \pm 0.47^{\mathrm{bc}}$ & $0.470 \pm 0.0032^{\mathrm{ab}}$ & $0.470 \pm 0.0033^{\mathrm{ab}}$ & $34.53 \pm 2.3^{\mathrm{a}}$ & $27.92 \pm 0.98^{\mathrm{a}}$ \\
\hline $\mathrm{T}_{4}$ & $4.12 \pm 0.19^{\mathrm{d}}$ & $7.26 \pm 0.61^{\mathrm{a}}$ & $7.03 \pm 0.42^{\mathrm{a}}$ & $25.13 \pm 0.70^{\mathrm{c}}$ & $0.450 \pm 0.0021^{\mathrm{bc}}$ & $0.493 \pm 0.0013^{\mathrm{ab}}$ & $34.76 \pm 1.9^{\mathrm{a}}$ & $27.75 \pm 0.77^{\mathrm{a}}$ \\
\hline
\end{tabular}


treatments. Results showed that the highest moisture content were present in extruded bread crumb in $\mathrm{T}_{2}$ and in oven baked bread crumb the highest moisture content was found in $\mathrm{T}_{4}$.

These results were in accordance with study of Yu and Augustine (2002) and Lucisano et al. (2010), who proposed that increased or decreased moisture content overall effect the texture and taste of bread crumb. If the moisture content is high then the bread crumb would be denser. The loss of moisture occurs rapidly during frying and the water replace with fat during frying and the products becomes too oily to taste and touch (Yu and Augustine, 2002).

The moisture content is affected as the temperature of barrel is changed. Moisture content (the quantitative determination of total water content) of final product determines the stability and quality of food material as moisture content of final product affects different nutritional as well as organoleptic properties of food and most importantly it determines the texture of product.

In baked products, the softness and tenderness is due to the moisture content and it helps in the chewing, enhancing palatability which is favourable for consumer. If the moisture is more than the required limit then promotes microbial growth and product is prone to spoilage however, much less quantity of final product makes the texture harder and less appealing and greatly affects the sensory properties of product.

Bulk density (g/100 L). Bulk density is defined as the "mass of particle occupied in a unit volume". Bulk density is not only useful descriptor of food texture but also describes the quality of extrudates. Bulk density is not an intrinsic property of a material it can change depending on how the material is handled. Screw speed and temperature during extrusion also affects the bulk density.

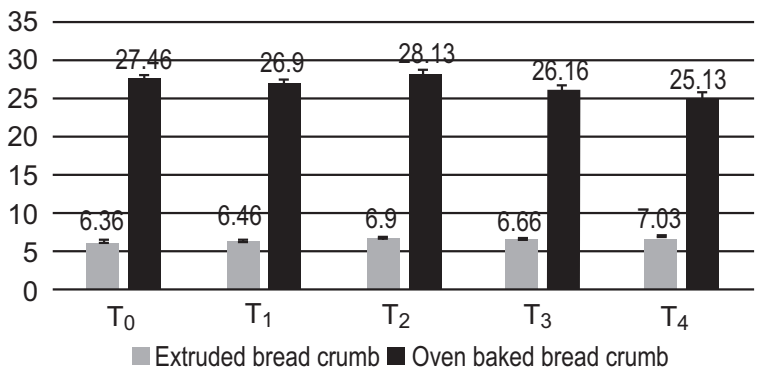

Fig. 2. Bulk density of extruded and oven baked bread crumb (G/100 L).
It is evident from the results that bulk density of extruded and oven baked bread crumb varied significantly (Fig. 2). The bulk density of extruded bread crumb ranged from 6.36 to $7.03 \mathrm{~g} / 100 \mathrm{~mL}$ while the bulk density of oven baked bread crumb varied from 25.13 to $28.13 \mathrm{~g} / 100 \mathrm{~mL}$ (Table 3). Significantly, the highest bulk density $(28.13 \mathrm{~g} / 100 \mathrm{~mL})$ of extruded bread crumbs was observed at lowest screw speed and at high moisture content while the highest bulk density $(7.03 \mathrm{~g} / 100 \mathrm{~mL})$ of oven baked bread crumbs was observed in $\mathrm{T}_{4}$. Bulk density is affected by the change of moisture content of the extruded and oven bread crumb which also affect the taste of bread crumb. The results are in accordance with findings of Lucisano et al. (2010) and Yu and Augustine (2002).

There was a specific interaction, between barrel temperature and expansion ratio keeping moisture content and screw speed constant. Overall expansion increased linearly with increasing temperature and screw speed up to $100^{\circ} \mathrm{C}$. An increase in temperature resulted in an increase in expansion and decrease in bulk density. Temperature was a dominant variable affecting macroscopic characteristics of extrudates. The different levels of temperature affected all macroscopic (expansion) properties of extrudates (Gautam and Choudhury, 1999). During extrusion, bulk density (BD) was influenced by temperature and it decreased with increasing temperature. If expansion increased it would be logical to assume that BD would decrease under similar conditions; but BD increased abruptly when temperature increased from 130 to $140{ }^{\circ} \mathrm{C}$. This could be due to the effect of high temperatures on viscosity and starch degradation resulting in less expansion (Grenus et al., 1993).

There is close relationship between bulk density and expansion ratio. When temperature of barrel is increased the expansion ratio rises to certain degree of temperature while the bulk density of extrudates show negative course of action in this regard (Altan et al., 2008). Increased process temperature, up to a certain point, increased expansion ratio and decreased $\mathrm{BD}$, but further increases in temperature decreased expansion ratio and increased BD. Bulk density decreased steadily as process temperature increased to a certain high temperature. Increasing process temperature from the lowest to the highest resulted in $46 \%$ increase in expansion ratio, $47 \%$ decrease in BD (Breen et al., 1977).

Fat uptake. Lipids are present in variable amount in many different foods. One of the components of lipids 
is glycerides that are mostly common. Lipids are richest source of energy and maintains the body temperature by providing heat energy by their oxidation but their excess usage can be harmful as they can lead to the chronic illness, such as heart disease, cancer and obesity (Sharma et al., 2004). It is evident from the results that fat uptake of extruded bread crumb has significant effect while fat uptake of extruded bread crumb also have significant effect.

The fat uptake of extruded bread crumb varied from $0.410 \mathrm{mg} / \mathrm{g}$ to $0.523 \mathrm{mg} / \mathrm{g}$ while that of oven baked bread crumb, it varied from $0.403 \mathrm{mg} / \mathrm{g}$ to $0.470 \mathrm{mg} / \mathrm{g}$ among different treatments (Table 3 ). The highest fat uptake of extruded bread crumb was observed in $T_{2}$ while highest fat uptake of oven baked bread crumb was observed in $\mathrm{T}_{4}$. It is clear from the results that fat uptake decreases slightly with gradually increase in temperature.

It shows that by increasing barrel temperature there is a little bit difference in degree of fat absorption of extrudates because at higher temperature and more low temperature extruder does not give proper product. At low temperature there is less water or moisture absorption and hence less disruption of bonding which results in less proper extrusion. At higher temperatures more than desired, there is burning of product and loss of nutrients including fat level and other minerals. The results are in accordance with findings of Lucisano et al. (2010) and $\mathrm{Yu}$ and Augustine (2002).

Fat addition lowers the barrel temperature of extruder due to the lubricating effect of fat and it ultimately decreases the starch gelatinisation during the extrusion process (Bredie et al., 2002). During extrusion, starch conversion can be reduced by the addition of fat as lubricator and shortening which ultimately prevent the severe mechanical breakdown of the starch granules by rotating screw and preventing water from being absorbed by starch. Reduced starch conversion/gelatinisation ultimately results in decreased expansion.

Water binding capacity ( $\left.\mathrm{g} \mathrm{H}_{2} \mathrm{O} / \mathbf{k g}\right)$. It is evident from the results that water binding capacity of extruded bread crumb has highly significant effect, while oven baked bread crumb has significant effect. The water binding capacity of extruded bread crumb varied from $28.96 \mathrm{~g}$ $\mathrm{H}_{2} \mathrm{O} / \mathrm{kg}$ to $34.76 \mathrm{~g} \mathrm{H}_{2} \mathrm{O} / \mathrm{kg}$ while, that of oven baked bread crumb, it varied from $27.15 \mathrm{~g} \mathrm{H}_{2} \mathrm{O} / \mathrm{kg}$ to $27.92 \mathrm{~g}$ $\mathrm{H}_{2} \mathrm{O} / \mathrm{kg}$ among different treatments (Table 3) and expressed in Fig. 3.

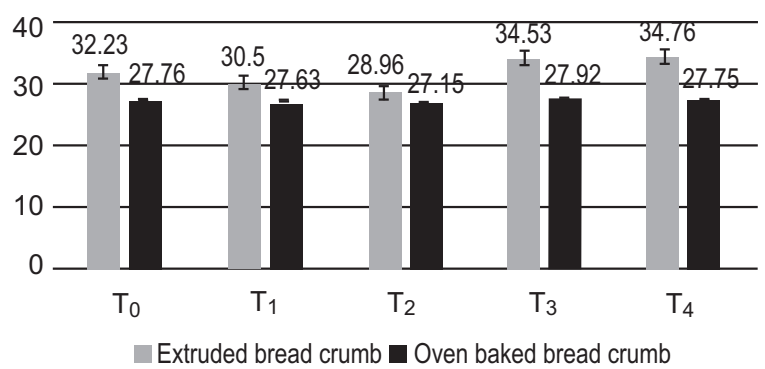

Fig. 3. Water binding capacity of extruded and oven baked bread crumb $\left(\mathrm{g} \mathrm{H}_{2} \mathrm{O} / \mathrm{kg}\right)$.

The highest water binding capacity $\left(34.76 \mathrm{~g} \mathrm{H}_{2} \mathrm{O} / \mathrm{g}\right.$ ) was observed in extruded bread crumb for highest temperature $\left(130^{\circ} \mathrm{C}\right)$ while, lowest extrusion temperature $\left(110^{\circ} \mathrm{C}\right)$ gave lower value of water binding capacity (28.96 $\mathrm{g} \mathrm{H}_{2} \mathrm{O} / \mathrm{g}$ ). It is also clear from results that water binding capacity increases with gradually increase in extrusion temperature. The highest water binding capacity (27.92 $\mathrm{g} \mathrm{H}_{2} \mathrm{O} / \mathrm{g}$ ) was observed in oven baked bread crumb. These results matched with Lucisano et al. (2010) and Tireki et al. (2006).

Water binding characteristics represent the ability of a product to gel formation of firmness when water has been added. Better taste, delay staling, softer crumb and prevention of water binding additives like corn, gums coating and for long time keep ability are the advantages of more water binding capacity. Water binding capacity increase with the increase in porosity (Tireki et al., 2006).

Expansion ratio of extruded bread crumb. It is evident from the results that the expansion ratio of bread crumb of extrudates has highly significant effect on temperature. The expansion ratio of bread crumb extrudates varied from $2.04,2.210,1.64,2.30$ and 2.53 for $\mathrm{T}_{0}$ to $\mathrm{T}_{4}$, respectively (Table 4). It is evident from the results that extrusion temperature significantly affects the expansion ratio of the bread crumb extrudates. The highest expansion ratio (2.53) was observed for highest temperature $\left(130^{\circ} \mathrm{C}\right)$ while at lower extrusion temperature $\left(110^{\circ} \mathrm{C}\right)$ gave lower value for bread crumb extrudates expansion ratio (1.64). It is also clear from these results that expansion ratio increase with gradually increase in temperature. The results were in accordance with findings of $\mathrm{Yu}$ and Augustine (2002).

By keeping constant the screw speed and moisture content, an interaction can be observed between expansion ratio and barrel temperature. Overall expansion increased 
Table 4. Means table regarding sensory attributes of extruded and oven baked bread crumb

\begin{tabular}{|c|c|c|c|c|c|c|c|c|c|c|}
\hline \multirow[b]{2}{*}{$\begin{array}{l}\text { Treat- } \\
\text { ment }\end{array}$} & \multicolumn{2}{|c|}{ Expansion ratio } & \multicolumn{2}{|c|}{ Flavour } & \multicolumn{2}{|c|}{ Taste } & \multicolumn{2}{|c|}{ Crispiness } & \multicolumn{2}{|c|}{ Over all acceptability } \\
\hline & $\begin{array}{l}\text { Extruded } \\
\text { bread } \\
\text { crumb }\end{array}$ & $\begin{array}{l}\text { Oven } \\
\text { baked } \\
\text { bread } \\
\text { crumb }\end{array}$ & $\begin{array}{l}\text { Extruded } \\
\text { bread } \\
\text { crumb }\end{array}$ & $\begin{array}{l}\text { Oven } \\
\text { baked } \\
\text { bread } \\
\text { crumb }\end{array}$ & $\begin{array}{l}\text { Extruded } \\
\text { bread } \\
\text { crumb }\end{array}$ & $\begin{array}{l}\text { Oven } \\
\text { baked } \\
\text { bread } \\
\text { crumb }\end{array}$ & $\begin{array}{l}\text { Extruded } \\
\text { bread } \\
\text { crumb }\end{array}$ & $\begin{array}{l}\text { Oven } \\
\text { baked } \\
\text { bread } \\
\text { crumb }\end{array}$ & $\begin{array}{l}\text { Extruded } \\
\text { bread } \\
\text { crumb }\end{array}$ & $\begin{array}{l}\text { Oven } \\
\text { baked } \\
\text { bread } \\
\text { crumb }\end{array}$ \\
\hline $\mathrm{T}_{0}$ & $2.04 \pm 0.012^{\mathrm{c}}$ & n.d. & $6.92 \pm 0.52^{\mathrm{a}}$ & $6.96 \pm 0.61$ & $6.50 \pm 0.19^{\mathrm{b}}$ & $5.93 \pm 0.24^{\mathrm{a}}$ & $5.36 \pm 0.43^{\mathrm{b}}$ & $6.96 \pm 0.55^{\mathrm{a}}$ & $6.80 \pm 0.53^{\mathrm{b}}$ & $6.07 \pm 0.45^{\mathrm{a}}$ \\
\hline $\mathrm{T}_{1}$ & $2.21 \pm 0.009^{\mathrm{bc}}$ & n.d. & $7.00 \pm 0.67^{\mathrm{ab}}$ & $6.80 \pm 0.31$ & $6.97 \pm 0.54^{\mathrm{a}}$ & $5.73 \pm 0.46^{\mathrm{a}}$ & $5.31 \pm 0.21^{\mathrm{ab}}$ & $6.76 \pm 0.42^{\mathrm{a}}$ & $6.67 \pm 0.19^{\mathrm{b}}$ & $5.80 \pm 0.31^{\mathrm{ab}}$ \\
\hline $\mathrm{T}_{2}$ & $1.64 \pm 0.014^{\mathrm{d}}$ & n.d. & $6.87 \pm 0.45^{\mathrm{abc}}$ & $6.65 \pm 0.48$ & $6.00 \pm 0.41^{\mathrm{c}}$ & $5.47 \pm 0.14^{\mathrm{b}}$ & $5.26 \pm 0.37^{\mathrm{abc}}$ & $6.50 \pm 0.31^{\mathrm{b}}$ & $6.36 \pm 0.42^{\mathrm{c}}$ & $5.53 \pm 0.24^{\mathrm{bc}}$ \\
\hline $\mathrm{T}_{3}$ & $2.30 \pm 0.004^{\mathrm{b}}$ & n.d. & $6.93 \pm 0.33^{\mathrm{bc}}$ & $6.96 \pm 0.39$ & $6.33 \pm 0.6^{\mathrm{b}}$ & $5.30 \pm 0.41^{\mathrm{bc}}$ & $5.43 \pm 0.49^{\mathrm{bc}}$ & $6.33 \pm 0.51^{\mathrm{b}}$ & $6.42 \pm 0.31^{\mathrm{c}}$ & $5.37 \pm 0.41^{\mathrm{c}}$ \\
\hline $\mathrm{T}_{4}$ & $2.53 \pm 0.023^{\mathrm{a}}$ & n.d. & $7.26 \pm 0.21^{\mathrm{c}}$ & $6.75 \pm 0.17$ & $7.00 \pm 0.34^{\mathrm{a}}$ & $5.10 \pm 0.33^{\mathrm{c}}$ & $5.70 \pm 0.17^{\mathrm{a}}$ & $6.25 \pm 0.26^{\mathrm{c}}$ & $6.99 \pm 0.36^{\mathrm{a}}$ & $5.57 \pm 0.36^{\mathrm{bc}}$ \\
\hline
\end{tabular}

n.d. $=$ not determined

linearly with increasing temperature and screw speed up to $130{ }^{\circ} \mathrm{C}$. An increase in temperature resulted in an increase in expansion and decrease in bulk density. Temperature was a dominant variable affecting macroscopic characteristics of extrudates. The different levels of temperature affected all macroscopic (expansion) properties of extrudates (Gautam and Choudhury, 1999). Starch can be able to expand in a better way as the temperature is increased and ultimately become fully cooked (Linko et al., 1982). They proposed that, increase in barrel temperature show a positive linear effect on expansion ratio of the final product. Also by gradual rise in temperature there is gradual rise in expansion ration of the extrudates and this occurs to a certain level of temperature which is $168{ }^{\circ} \mathrm{C}$. They suggested the existence of temperature plateau for expansion, between 150 and $170{ }^{\circ} \mathrm{C}$ depending on the type of food material. This phenomenon may be caused by excessive structure breakdown and starch degradation under high temperature which weakened the extrudate structure and therefore, caused it to collapse. But at $160{ }^{\circ} \mathrm{C}$ there was gradual increase in expansion ratio of the extruded product due to gelatinisation of starch content of raw material.

Sensory evaluation. Flavour. Quality is perceived by the consumer's attitude and liking. Flavour is one of the important attributes in the purchasing ability of consumer. As our taste buds are encountered with any of the food commodity being composed of either sweet, salty, sour, and bitter or umami, the receptors will automatically detect the respective flavour sensation. A panel of trained sensory analysts determined the flavour of the food stuffs. It is evident from the results that the extruded bread crumb has significant effect on sensory evaluated flavour while the oven baked bread crumb has non-significant effect on flavour.
The sensory evaluation values for flavour of cutlass coated with extruded bread crumb varied from 6.87 to 7.26 while, that of coating of oven baked bread crumb, it varied from 6.65 to 6.96 among different treatments (Table 4) and expressed in Fig. 4. It is evident from results that extrusion temperature affects the sensory evaluated flavour of the extruded bread crumb. The values of coated bread crumb on cutlass are in the range of liking flavour attributes.

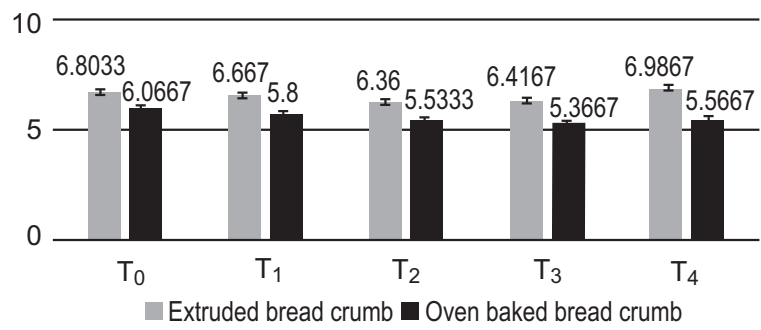

Fig. 4. Overall acceptability scores of extruded and oven baked bread crumb.

The highest sensory evaluated flavour (7.26) was observed at highest temperature $\left(130^{\circ} \mathrm{C}\right)$ while at lower extrusion temperature $\left(110^{\circ} \mathrm{C}\right)$ gave lower value for bread crumb extrudates sensory evaluated flavour (6.87). It is also clear from these results that sensory evaluated flavour increases with gradually increase in temperature.

The results of oven baked bread crumb match with the results given by Al-Abdullah et al. (2011). The results of extruded bread crumb match with the results given by $\mathrm{Yu}$ and Augustine (2002). He reported that by increasing temperature of extrusion, flavour is developed in extruded product due to activation of flavour producing compounds at higher temperature. 
Bhandari et al. (2001) defines flavour as the "sensory manifestation" for the perception of products in terms of their:

(1) Reaction to taste by the kinesthetic sense in the muscles of the hand, fingers, tongue, jaw, or lips (e.g. adhesiveness, cohesiveness, hardness, etc.), and

(2) Tactile feel properties measured by the tactile nerves in the surface of the skin of the hand, lips, or tongue (e.g. oiliness, tenderness, moistness, etc.).

Taste. The taste is the most important factor that, consumers consider when shopping for food. It is evident from the results that the extruded bread crumb has highly significant effect on sensory evaluated taste while the oven baked bread crumb also has highly significant effect. The mean values of sensory evaluated taste of cutlass coated with extruded bread crumb varied from 6.00 to 7.00 while in cutlass with coating of oven baked bread crumb, it varied from 5.10 to 5.9 among different treatments (Table 4). It is evident from results that extrusion temperature affects the sensory evaluated taste of the extruded bread crumb. The values of coated bread crumb on cutlass are in the range of liking and fairly liking taste attributes.

The highest score for taste (7.00) was observed for highest temperature $\left(130^{\circ} \mathrm{C}\right)$ while lower extrusion temperature $\left(110^{\circ} \mathrm{C}\right)$ gave lower value for bread crumb extrudates sensory evaluated taste (6.00). It is also clear from the results that sensory evaluated taste of extruded bread crumb increases with gradually increase in temperature.

The results of oven baked bread crumb match with the results given by Al-Abdullah et al. (2011). The results of extruded bread crumb match with the results given by $\mathrm{Yu}$ and Augustine (2002). He reported that by increasing temperature of extrusion taste is developed in extruded product due to lowering the moisture of product. He proposed that when temperature of processing technique is increased to a certain degree it produce a desirable taste in the product and when temperature was low then the cooked food has not desirable taste characteristics. This is because when temperature is raised in extrusion cooking it results in cooking of product and removing and disruption of certain components which affect the taste of product in negative way. In this way in present study, application of $130{ }^{\circ} \mathrm{C}$ in $\mathrm{T}_{4}$ showed most acceptable taste.
Crispiness. The crispiness plays a crucial role in the enjoyment of eating foods. Crunchy in an otherwise smooth dish, may increase the appeal of eating it. Crispiness is also important parameter of the product to determine its quality with respect to its sensory characteristics. And also an important characteristic in consumer's perception of food and purchasing decisions. The results regarding the analysis of variance of extruded bread crumb was significant while the oven baked bread crumb of sensory evaluated crispiness was highly significant. The values of sensory evaluated crispiness of cutlass coated extruded bread crumb varied from 5.26 to 5.70 while that of coating of oven baked bread crumb, it varied from 6.25 to 6.96 among different treatments (Table 4). It is evident from the results that the extruded bread crumb has highly significant effect on sensory evaluated crispness while the oven baked bread crumb also has highly significant crispiness. It is evident from results that extrusion temperature affects the sensory evaluated crispiness of the extruded bread crumb. The values of coated bread crumb on cutlass are in the range of liking and fairly liking taste attributes.

The highest sensory evaluated crispiness (5.70) was observed for highest temperature $\left(130^{\circ} \mathrm{C}\right)$ while lower extrusion temperature $\left(110^{\circ} \mathrm{C}\right)$ gave lower value for bread crumb extrudates sensory evaluated crispiness (5.26). It is also clear from results that sensory evaluated crispiness of extruded bread crumb increases with gradually increase in temperature. Low moisture in bread crumb give lower density which causes the bread crumb to uptake low fat and create white crystal spot which enhance the look of the product and also make the product crispy.

The results of oven baked bread crumb match with the results given by Salvador et al. (2008). The results of extruded bread crumb match with the results given by $\mathrm{Yu}$ and Augustine (2002). He proposed that when temperature of processing technique is increased to a certain degree it produce a desirable crispiness in the product as its human perception by senses to observe the taste of product. But if temperature is low, the cooked food has not given desirable crispiness texture.

The results were in accordance of $\mathrm{Yu}$ and Augustine (2002), according to him by increasing the barrel temperature the maximum bond disruption occurs results in formation of more homogeneous laminate along barrel, hence imparting better textural characteristics. 
Overall acceptability. The overall acceptability is also important parameter of the product to determine its quality with respect to its sensory characteristics. It is evident from the results that high significant effect on overall acceptability of extruded and oven baked bread crumb.

The values of sensory evaluated over all acceptability of cutlass coated extruded bread crumb varied from 6.36 to 6.98 while, that of coating of oven baked bread crumb, it varied from 5.36 to 6.06 among different treatments (Table 4) and graphically expressed in Fig. 5.

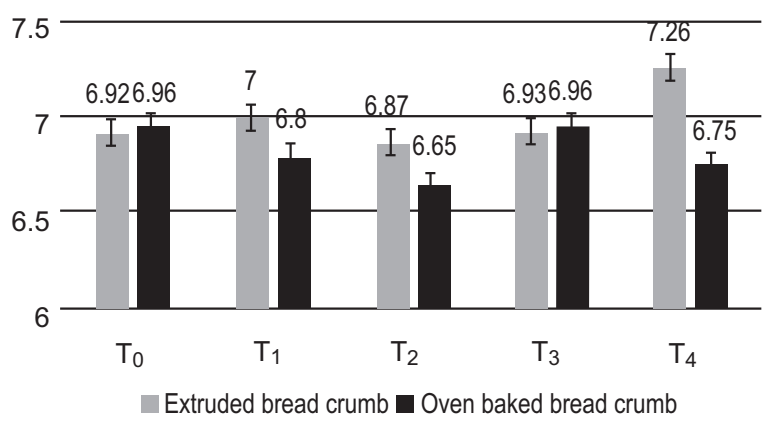

Fig. 5. Flavour scores of extruded and oven baked bread crumb.

The highest overall acceptability (6.98) was observed for highest temperature $\left(130^{\circ} \mathrm{C}\right)$ while, lower extrusion temperature $\left(110^{\circ} \mathrm{C}\right)$ gave lower value for bread crumb extrudates overall acceptability (6.36). It is also clear from results that overall acceptability increases with gradually increase in temperature. The highest overall acceptability of oven baked bread coating is (6.06). The values of coated bread crumb on cutlass are in the range of liking and fairly liking overall acceptable. The results of oven baked bread crumb match with the results given by Al-Abdullah et al. (2011). The results of extruded bread crumb match with the results given by $\mathrm{Yu}$ and Augustine (2002).

\section{Conclusion}

The characteristics of the sample extruded at $110{ }^{\circ} \mathrm{C}$ showed bulk density and fat uptake properties that were more acceptable. The study clearly showed that the good functionality of extruded bread crumb was highly dependent on the extrusion processing conditions. Comparing to the oven baked bread crumb, the extruded bread crumb showed good functionality in relation to the control and considering further, the effect of ingredient on the texture of extruded bread crumb, some ingredient can be excluded without adverse effect thus the crisp texture and maximum expansion of extruded bread crumb may be obtained by selecting the following extrusion processing conditions; barrel moisture content $27 \%$; screw speed $150 \mathrm{rpm}$; barrel temperature $110^{\circ} \mathrm{C}$; flow rate $55-61 \mathrm{~kg} / \mathrm{h}$; cut at die face and a cost effective formulation comprising of wheat flour (85.3\%); soy flour (5\%); emulsifier ( $0.3 \%$ ); salt (2\%); baking powder (4\%). On the basis of this study, extrusion cooking for the production of bread crumb is recommended because with extrusion, some of the ingredients can be removed from the formulation without adverse effect probably due to the interplay between extrusion conditions during cooking. Extrusion thus reduces the cost of input than oven baked. Similarly, less time is required for the process.

Hence, it is concluded that $T_{2}$ treatment of extruded bread crumb is efficient, cheap, and good sensory, and also perform overall well then oven baked bread crumb.

\section{References}

AACC, 2000. Approved Methods of American Association of Cereal Chemists. The American Association of Cereal Chemists. Inc. St. Paul. Minnesota, USA.

Al-Abdullah, B., Angor, M., Al-Ismail, K., Ajo, R. 2011. Reducing fat uptake during deep-frying of minced chicken meat-balls by coating them with some hydrocolloids materials. Italian Journal of Food Science, 23: 331-337.

Altamirano-Fortoul, R., Le-Bail, A., Chevallier, S., Rosell, C.M. 2012. Effect of the amount of steam during baking on bread crust features and water diffusion. Journal of Food Engineering, 108: 128134.

Altan, A., McCarthy, K.L., Maskan, M. 2008. Evaluation of snack foods from barley-tomato pomace blends by extrusion processing. Journal of Food Engineering, 84: 231-242.

Bhandari, B., Darcy, B., Young, G. 2001. Flavor retention during high temperature short time extrusion cooking process: A review. International Journal of Food Science and Technology, 36: 453-461.

Bredie, W.L.P., Mottram, O.S., Guy, R.C.E. 2002. Effect of temperature and $\mathrm{pH}$ on the generation of flavor volatiles in extrusion cooking of wheat flour. Journal of Agricultural and Food Chemistry, 50: 1118-1125. 
Breen, M.D., Seyam, A.A., Banasik, O.J. 1977. The effect of mill byproducts and soy protein on the physical characteristics of expanded snack foods. Cereal Chemistry, 54: 728.

Colonna, P., Melcion, J.P., Vergnes, B., Mercier, C. 1983. Flow, mixing and residence time distribution of maize starch with in a twin-screw extruder with a longitudinally split barrel. Journal of Cereal Science, 1: 115-121.

Gautam, A., Choudhury, G.S. 1999. Screw configuration effects on starch breakdown during twin-screw extrusion of rice flour. Journal of Food Processing and Preservation, 23: 355-375.

Grenus, K., Hsieh, F., Huff, H. 1993. Extrusion and extrudate properties of rice flour. Journal of Food Engineering, 18: 229-245.

Guy, R. 2001. Extrusion Cooking Technologies and Application. pp. 3-5, Cambridge Wood Head Publishing Ltd., UK.

Hug-Iten, S., Handschin, S., Conde-Petit, B., Escher, F. 1999. Changes in starch microstructure on baking and staling of wheat bread. LWT-Food Science and Technology, 32: 255-260.

Hwang, M.P., Hayakawa, H.I. 1980. Bulk densities of cookies undergoing commercial baking processes. Journal of Food Science, 45: 1400-1407.

Ilo, S., Berghofer, E. 1999. Kinetics of color changes during extrusion cooking of maize grits. Journal of Food Engineering, 39: 73-80.

Lawless, H.T., Heymann, H. 1998. Sensory Evaluation of Food: Principles and Practices, pp. 227-257, Chapman and Hall, New York, USA.

Linko, P., Linko, Y.Y., Olkku, J. 1982. Extrusion cooking and bioconversions. Journal of Food Engineering, 2: 243-257.

Lucisano, M., Cappa, C., Fongaro, L., Mariotti, M. 2010. Methods for the characterization of bread- crumb, an important ingredient of stuffed pasta. Journal of Cereal Science, 51: 381-387.

Pajak, P., Celina, H., Habryka, T. 2012. Changes in the physical properties of bread during storage. Journal of Food Science, 6: 42-45.

Rosell, C.M. 2009. Trends in bread making: low and subzero temperatures. In: Innovation in Food Engineering: New Techniques and Products. M. L. Passos, C. L. Ribeiro (eds.), pp. 59-79, Taylor and Francis, CRC Press, .

Salvador, A., Sanz, T., Fiszman, S. 2008. Performance of methyl cellulose in coating batters for fried products. Food Hydrocolloids, 22: 1062-1067.

Sharma, H.R., Chauhan, G.S., Agrawal, K. 2004. Physico-chemical characteristics of rice bran processed by dry heating and extrusion cooking. International Journal of Food Properties, 7: 603614.

Shittu, T., Raji, A., Sanni, L. 2007. Bread from composite cassava-wheat flour: Effect of baking time and temperature on some physical properties of bread loaf. Food Research International, 40: 280-290.

Steel, R.G.D., Torrie, J.H., Dickey, D. 1997. Principles and Procedures of Statistics: A Biometrical Approach. $3^{\text {rd }}$ edition, McGraw Hill Book Co., Inc., New York, USA.

Tireki, S., Sumnu, G., Esin, A. 2006. Production of bread crumbs by infrared-assisted microwave drying. European Food Research and Technology, 222: 8-14.

Vanin, F., Lucas, T., Trystram, G. 2009. Crust formation and its role during bread baking. Trends in Food Science and Technology, 20: 333-343.

Yu, J.Z., Augustine, A. 2002. Effect of extrusion cooking on the properties and acceptability of bread-crumblike coating products. International Journal of Food Properties, 5: 573-584. 